\title{
Pilot Study on Gas Patterns of Irritable Bowel Syndrome and Small Intestinal Bacterial Overgrowth Following Ingestion of Lactulose
}

\author{
Yoshiharu Uno ${ }^{1,2}$ \\ ${ }^{1}$ Office Uno Colum, Hyogo, Japan \\ ${ }^{2}$ Oroku-Hospital, Okinawa, Japan \\ Email:yoshiharu333@hotmail.com
}

Received 6 October 2015; accepted 13 November 2015; published 16 November 2015

Copyright (C) 2015 by author and Scientific Research Publishing Inc.

This work is licensed under the Creative Commons Attribution International License (CC BY). http://creativecommons.org/licenses/by/4.0/

(C) (i) Open Access

\begin{abstract}
Background \& Aims: Fermentation site and increasing time of symptomatic gas would be different between irritable bowel syndrome (IBS) and small intestine bacterial overgrowth (SIBO). The aim of this study was to determine the time for increase in abdominal gas following ingestion of lactulose and the possibility of differential diagnosis of SIBO and IBS. Methods: A prospective study was conducted on a series of IBS patients $(n=14)$ who were referred to the Oroku-Hospital (Okinawa, Japan) from June 6, 2014 to December 30, 2014. Imaging was first performed in early morning after fasting. After ingestion of lactulose, 1 - 4 plain abdominal radiographs were taken for investigation of increased gas during the indicated timeframe. Regions of interest of the gas areas were highlighted on the images obtained. Gas images were divided into three areas, the stomach, small intestine, and large intestine, and each total area was calculated. Results: At a dose of $10 \mathrm{~g}$ lactulose and an observation time of two hours, patients displayed no symptoms, and the gas volume was only slightly increased. However, when the dose of lactulose was increased (13 g/50 kg), and the observation time for the lactulose challenge was extended to 240 - 300 minutes, the results clearly demonstrated an increase in the gas produced in IBS patients. Conclusions: An increased dose of lactulose coupled with an extended observation time for the lactulose challenge clearly demonstrated an increase in the gas produced in IBS patients. Alterations in diet rather than antibiotics might reduce IBS symptoms.
\end{abstract}

\section{Keywords}

Irritable Bowel Syndrome (IBS), Small Intestine Bacterial Overgrowth (SIBO), Lactulose, Radiography 


\section{Introduction}

The relationship of irritable bowel syndrome (IBS) and small intestinal bacterial overgrowth (SIBO) remains obscure [1]-[3]. SIBO is a syndrome characterized by an increased number of bacteria in the small intestine. Since culture tests of directly aspirated jejunal-fluid are invasive, breath tests are popularly used to diagnose SIBO. When colonic bacteria colonize the small intestine, as in SIBO, many gases are produced by fermentation of carbohydrates in the small intestine. These gases readily diffuse into the abdominal venous circulation and are transported to the lungs, where they are detected in the exhaled breath [4] [5].

The lactulose breath test (LBT) is the most widely used breath test for the detection of the gases produced in SIBO. In this method, after the administration of $10 \mathrm{~g}$ of the lactulose, breath samples are taken at $15-20$ minute intervals over 3 hours [3]. Generally, SIBO is diagnosed by the appearance of an early first peak of hydrogen, within 90 minutes after lactulose ingestion [1] [3]. With this method, it was reported in 2000 that SIBO was present in $78 \%$ of IBS, and that IBS symptoms were improved by treatment with antibiotics [6]. However, in subsequent studies, the incidence of SIBO in IBS was reported to be not as high [7]-[13].

Several investigators have suggested, however, that LBT cannot be used to diagnose IBS, because the test could not distinguish IBS patients from healthy controls [14] [15]. Nevertheless, effectiveness of the eradication of IBS was reported, as bacterial growth was implicated in development of the syndrome [16]. Therefore, eradication therapy for IBS may be indicated based on the assumption of gastrointestinal bacterial overgrowth without an actual diagnosis of SIBO [4] [5]. In other words, even though involvement of SIBO in IBS is unclear, eradication therapy has been promoted [17].

Symptoms of SIBO closely parallel symptoms of IBS [1]. Symptoms include abdominal distension, bloating, and abdominal pain, and their cause can be attributed to an increase in the gas produced [18]-[20]. In other words, even though involvement of SIBO in IBS is unclear, eradication therapy has been promoted [21]-[24]. Theoretically, abdominal gas is not always constant even within individuals as the volume of gut gas may be influenced by the contents of the meal and time after ingestion. Therefore, the discrepancy in results might simply be due to the timing of the gas measurement in various studies. In addition, there has been no report concerning increased gas volume in small intestine in SIBO. Furthermore, a relationship between gas of IBS and gas of SIBO has never been examined.

In a recent study, it was found that small intestinal transit time was delayed in the case of SIBO [24] [25]. This result indicates that fermentation possibly occurs continuously for several hours after food intake in the small intestine of SIBO. Therefore, there is potentially no scientific basis for SIBO diagnostic criteria for LBT, and the hydrogen peak within 90 minutes might only be a theory based on a relationship to anatomical location. Although the breath hydrogen is increased by fermentation in the large and small intestine after ingestion of lactulose, exactly where, when, and how much gas is increased remains unknown. Here, the gas volume was measured by radiography after lactulose dose over time. The original purpose of the present study was to determine the time for increase in abdominal gas following ingestion of lactulose. The possibility of differential diagnosis of SIBO and IBS was subsequently evaluated.

\section{Methods}

\subsection{Ethics Statement}

The study was conducted in accordance with the 1975 Declaration of Helsinki, after approval of the ethics committee of Oroku Hospital (Okinawa, Japan) in May 7, 2014. Patients were fully informed of the purpose of the study, the methods, and the possible side effects of the procedures. Written informed consent was obtained from each patient. The protocol for this study is registered with the University Hospital Medical Information Network (UMIN) Clinical Trials Registry, No.UMIN000018422.

\subsection{Study Patients}

A prospective study was conducted on a series of IBS patients ( $n=14 ; 12$ women; 2 men) who were referred to this study at Oroku-Hospital (About 1000 hospitalized patients per year. Okinawa, Japan,) from June 06, 2014 to December 30, 2014. Their mean age was 47.0 years ( \pm 22.4 years, $17-81$ years), and the mean body weight was $50 \mathrm{~kg}( \pm 5.0 \mathrm{~kg}, 46-63 \mathrm{~kg})$. According to the Rome III criteria [26], patients were divided into three types of IBS: constipation-predominant IBS ( $\mathrm{n}=8$ patients); alternating-type IBS ( $\mathrm{n}=5$ patients), and diarrhea-predo- 
minant IBS ( $\mathrm{n}=1$ patient). Patient 6 did not match the exclusion criteria of IBS. Although he had Crohn's disease 11 years before, he was in complete remission before this study began, but had symptoms of alternating IBS. Because the patient had undergone gastro-jejunostomy 10 years before the study, IBS with SIBO was suspected in his case.

\subsection{Measurement of Gas Volume}

In the first half of the study ( $\mathrm{n}=5$ patients), $10 \mathrm{~g}$ of lactulose (Monilac; Chugai Pharmaceutical Co., Ltd.; Tokyo, Japan) with $150 \mathrm{~mL}$ water was used the same as normal LBT, and the observation time was within 120 min. In Japan, Monilac is used as a therapeutic agent for hyperammonemia of cirrhosis; the dose is 19.5 - $39 \mathrm{~g}$ per day. In the second half of the study ( $\mathrm{n}=9$ patients), lactulose was increased to $13 \mathrm{~g}$, and the observation time was extended to 240 - 300 min. Gas volumes were measured based on the plain abdominal supine radiographs. Imaging was first performed in early morning after fasting. After ingestion of lactulose, the patient was instructed to move and walk as in everyday life, and 1 - 4 plain abdominal radiographs were subsequently taken for investigation of increased gas during the indicated timeframe. The appearance of symptoms of patients was confirmed by X-ray imaging. The gas area was measured with the radiographic software PACS (Figure 1; Processor Array for Continuum Simulation; Hitachi, Ltd.; Tokyo, Japan) which was incorporated into the X-ray imaging monitor. Tracing of the gas areas were thus directly superimposed on the images obtained. Gas images were divided into three areas, the stomach, small intestine, and large intestine, and each total area was calculated. Imaging for all patients was performed on one machine with the same imaging monitor and software. The areas of gas were measured at one magnification. In order to obtain reliable results, the images were reanalyzed three times, and an average of the total was defined as the total gas area (TGA).

\subsection{Statistical Analysis}

The major goal of the study was to compare gas measurements with $10 \mathrm{~g}$ lactulose and observation within 120 min to gas measurements with $13 \mathrm{~g}$ lactulose and observation of 240 - 300 minutes. For confirmation of the utility of the second measurement, P values, were determined by a two-tailed Student's t-test (hazard ratio of 5\%), when compared to the gas area before lactulose ingestion.

\section{Results}

To test the methods for measurement of TGA and thus IBS versus SIBO, the 14 patients were separated into two groups, with 5 patients ingesting $10 \mathrm{~g}$ of lactulose and 9 patients ingesting $13 \mathrm{~g}$ (Table 1 ). The mean TGA for all patients before ingestion of lactulose was $79.0 \mathrm{~cm}^{2}\left( \pm 52.0 \mathrm{~cm}^{2}, 39.0-191.3 \mathrm{~cm}^{2}\right)$. The TGA increased during the observation time, and the rate of the increase was an average of 2.3-fold (range: 1.4 - 7.6-fold). Symptoms were not observed within the two-hour observation period after ingestion of $10 \mathrm{~g}$ lactulose for any patient. However, with ingestion of $13 \mathrm{~g}$ of lactulose, symptoms were observed in 66.7\% (6/9) of patients within 5 hours. Patient 7 , one of the patients without symptoms, exhibited a high TGA before the test, so that the rate of increase of the TGA (1.3) during the test was the lowest. Therefore, even though the final TGA was as high as $233 \mathrm{~cm}^{2}$, symptoms were not recognized during the observation time.

Some patterns were observed in the stomach, small intestine, and large intestine of the gas area (Figure 2 and Figure 3). The main pattern (Figure 3(a); Type-L; large intestine gas type) was increased gas (85.7\%) in the large intestine in the absence of changes in the small intestine gas within a short time period. In Type-L, subtypes of increased stomach gas after 30 min and increased small intestinal gas after 300 minutes appeared in two patients. An additional two characteristic patterns were observed. Patient (patient 9) exhibited increased small intestinal gas without increased large intestinal gas (Figure 3(b); Type-S; small intestine gas type), or (patient 6) was increasing gas of both the large and small intestines (Figure 3(c); Type-M; mixed type). There was no specific regularity observed in the changes of the gas area in the stomach. Finally, comparison of the two methods of measurement, $10 \mathrm{~g}$ lactulose and observation over $120 \mathrm{~min}$ and $13 \mathrm{~g}$ lactulose and observation over 240 - 300 min (Figure 4), revealed that the latter approach was more effective in measuring changes in gas relative to the gas area present before the ingestion of lactulose $(P=0.01306$ and $P=0.00108$, respectively).

\section{Discussion}

Improvements in the imaging for gas volume in IBS patients were proposed to help to establish whether symptoms 


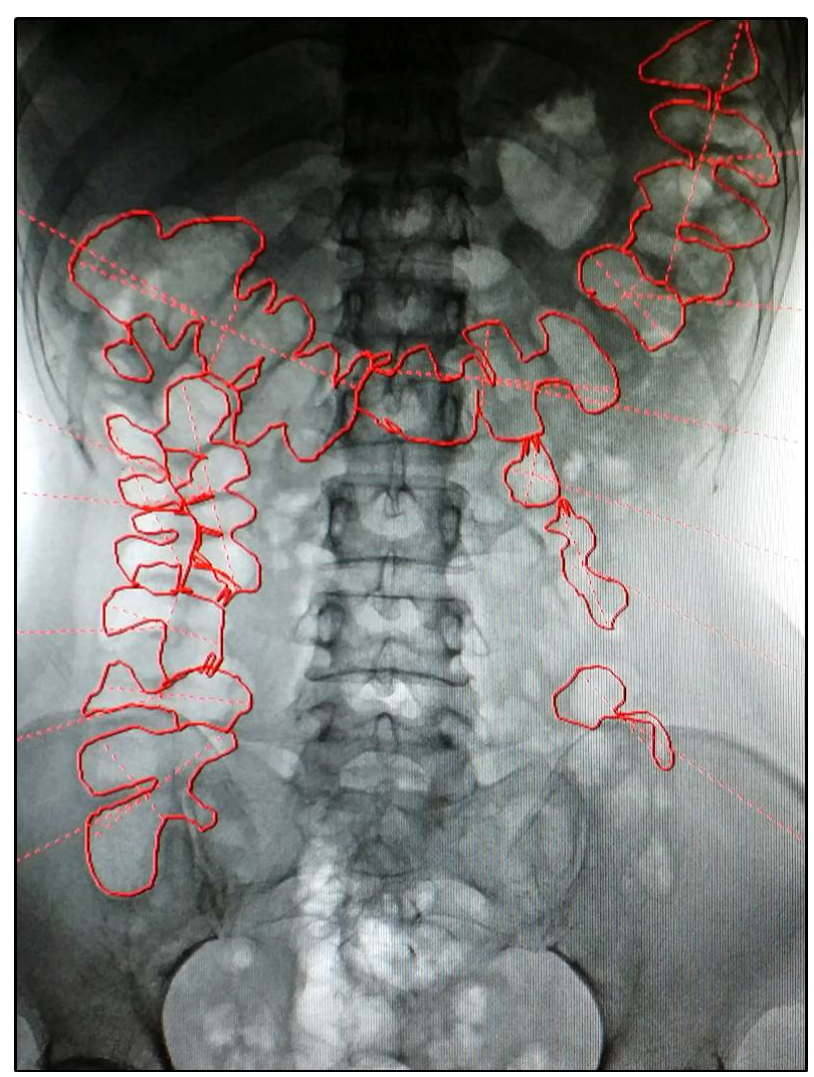

Figure 1. Calculation method of gas area. Regionsof interest are outlined in red. The area was recorded for each region of interest. Location of each region of interest was further divided into stomach, small intestine, and large intestine. The sum of the regions of interest was the total gas area for each anatomical section.

Table 1. Patient profiles and results.

\begin{tabular}{|c|c|c|c|c|c|c|c|c|c|c|c|c|c|c|}
\hline Patient & Age (y) & Sex & BW(kg) & IBS Symptom & L (g) & Before $\left(\mathrm{cm}^{2}\right)$ & $\begin{array}{c}30 \mathrm{~min} \\
\left(\mathrm{~cm}^{2}\right)\end{array}$ & $\begin{array}{c}60 \text { min } \\
\left(\mathrm{cm}^{2}\right)\end{array}$ & $\begin{array}{c}90 \text { min } \\
\left(\mathrm{cm}^{2}\right)\end{array}$ & $\frac{120 \min }{\left(\mathrm{cm}^{2}\right)}$ & $\begin{array}{c}240 \text { min } \\
\left(\mathrm{cm}^{2}\right)\end{array}$ & $\begin{array}{c}300 \text { min } \\
\left(\mathrm{cm}^{2}\right)\end{array}$ & GIR & Symtome \\
\hline 1 & 77 & W & 49 & Constipation & 10 & 43.2 & 99.4 & 135.3 & 138.2 & & & & 3.2 & Negative \\
\hline 3 & 51 & W & 46 & Constipation & 10 & 39.0 & 51.8 & 80.3 & & 127.2 & & & 3.3 & Negative \\
\hline 4 & 35 & W & 50 & Altterationg & 10 & 75.7 & & 93.6 & & 107.9 & & & 1.4 & Negative \\
\hline 6 & 35 & M & 63 & Alternating & 13 & 191.3 & 242.9 & 298.0 & & 341.8 & 312.5 & & 1.8 & Bloating \\
\hline 7 & 22 & $\mathrm{~W}$ & 48 & Constipation & 13 & 185.0 & & & & 213.2 & 233.0 & & 1.3 & Negative \\
\hline 8 & 60 & $\mathrm{~W}$ & 46 & Constipation & 13 & 60.4 & & & & & 176.0 & 201.9 & 3.3 & Bloating \\
\hline 9 & 70 & M & 57 & Alternating & 13 & 72.5 & & & & & 160.5 & 234.6 & 3.2 & Bloating \\
\hline 10 & 75 & W & 52 & Alternating & 13 & 18.1 & & & & & 45.0 & 137.5 & 7.6 & Blosting \\
\hline 11 & 17 & W & 46 & Constipation & 13 & 64.1 & & & & & 86.1 & 185.6 & 2.9 & Negative \\
\hline 12 & 81 & W & 48 & Constipation & 13 & 58.2 & & & & & & 116.9 & 2.0 & Negative \\
\hline 13 & 29 & $\mathrm{~W}$ & 48 & Alternating & 13 & 79.8 & & & & & & 170.0 & 2.1 & Pain \\
\hline 14 & 20 & W & 50 & Constipation & 13 & 113.6 & & & & & & 206.2 & 1.8 & Bloating \\
\hline AVG & 47 & & 50 & & & 79.0 & 122.5 & 125.8 & 125.1 & 168.9 & 168.9 & 179.0 & 2.3 & \\
\hline
\end{tabular}

$\mathrm{W}=$ woman; $\mathrm{M}=$ man; IBS = irritable bowel syndrome; $\mathrm{BW}=$ body weight $(\mathrm{kg})$; $\mathrm{L}$ = ingested lactulose dose (g); Before = total gas volume before ingestion the lactulose; time $\left(\mathrm{cm}^{2}\right)=$ total gas area $\left(\mathrm{cm}^{2}\right)$ at time indicated following lactulose ingestion; GIR = gas increased rate (ratio of the maximum area of gas and the minimum area of gas); Symptom = Symptoms that occurred during the test; AVG = Average; Blank indicates that no radiography was performed. 


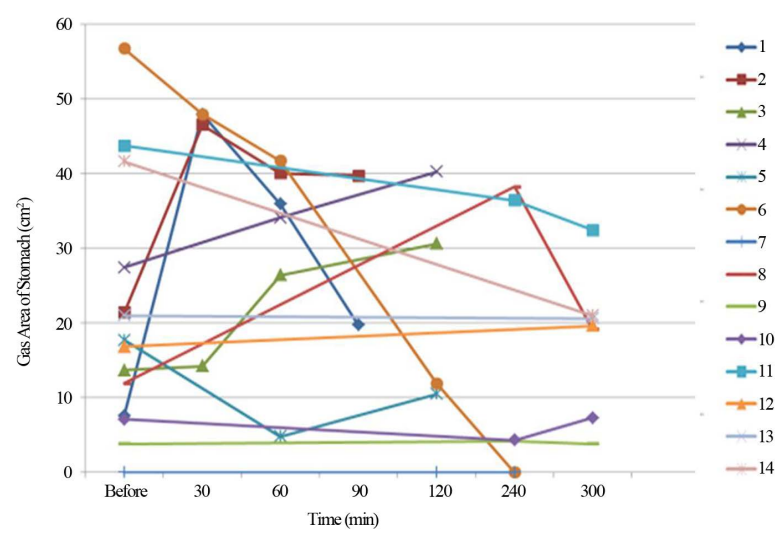

(a)

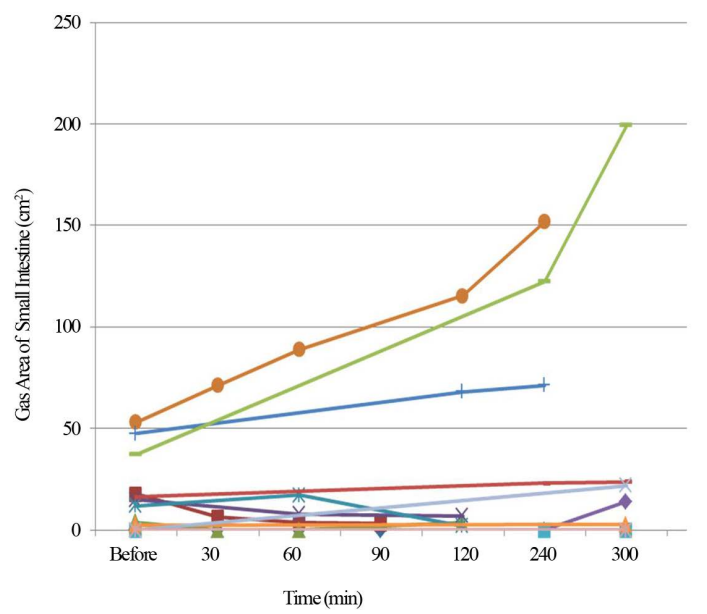

$\rightarrow-1$
$\sharp-2$
$\rightarrow-3$
-4
-5
$\rightarrow-6$
-7
-8
-9
$\rightarrow-10$
-11
-12
-13
-14

(b)

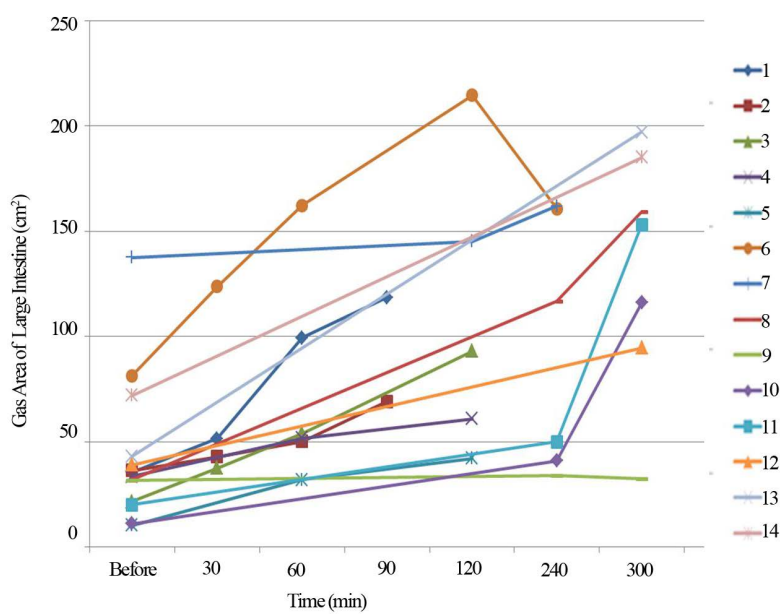

(c)

Figure 2. Change in gas area over time for each patient. Total gas areas $\left(\mathrm{cm}^{2}\right)$ of each tractwere plotted as a function of time for each patient. Results are separated based on location in the stomach (a), small intestine (b), or largeintestine (c). (Transient increase of the gas area in the stomach was observed in three patients. In patient 6 , gas area decreased over time. However, gas areas of the stomach for all patients was $\leq 60 \mathrm{~cm}^{2}$. Increase of more than twice the gas area in the small intestine was observed in two cases (patient 6 and patient 9). With the exception of these two patients (patient 6 and patient 9), gas areas of the large intestine increased over time. In patient 6 , gas area decreased at $240 \mathrm{~min}$. In patient 9, large intestine gas areas did not increase during the observation time). 


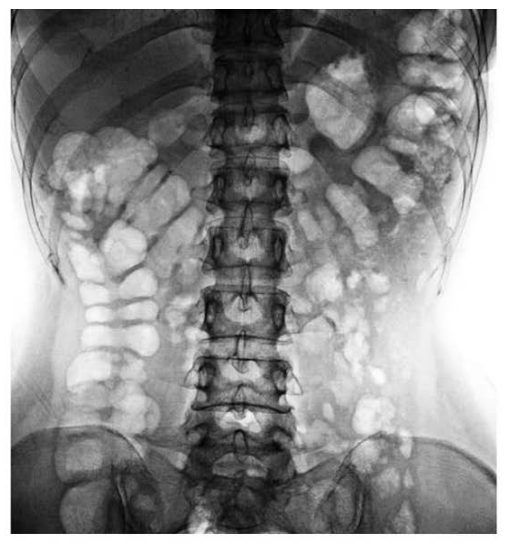

Final Image (300 min)

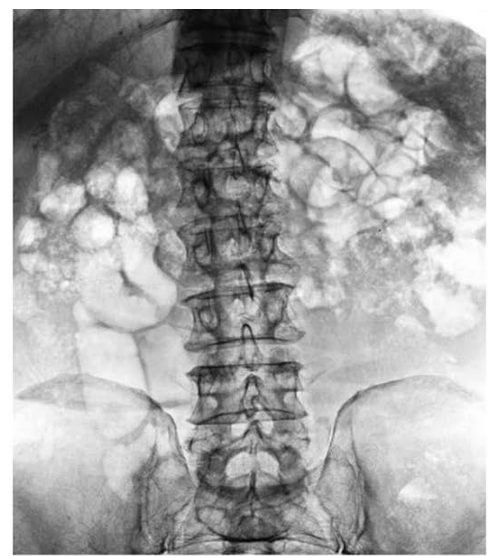

Final Image (300 min)

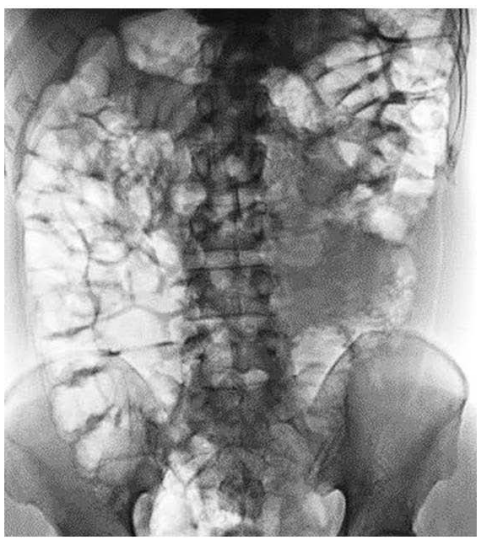

Final Image $(240 \mathrm{~min})$

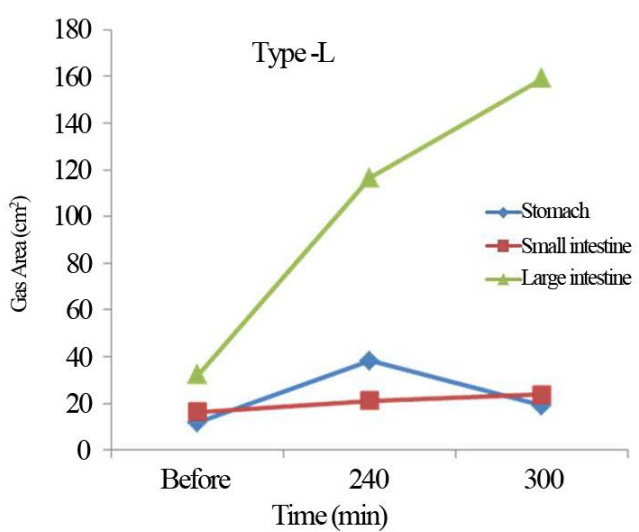

(a)

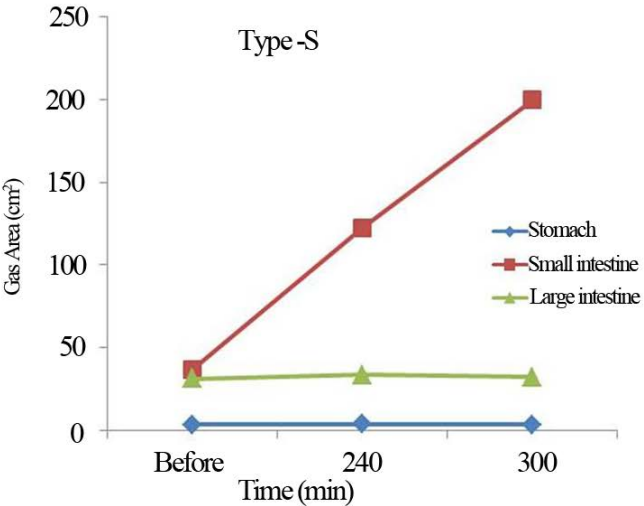

(b)

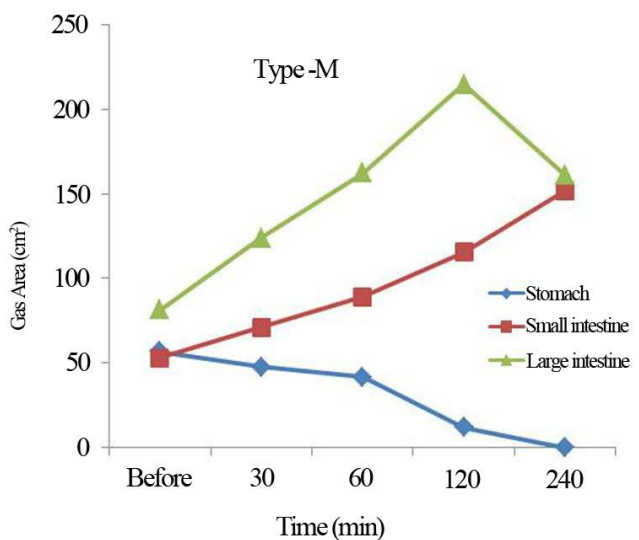

(c)

Figure 3. Three patterns of gas area and characteristic radiographs. In type-L (a), gas in large intestine is increased as a result of fermentation in the large intestine. The diagnosis is IBS without SIBO. In type-S (b), gas in small intestine is potentially increased by fermentation and overgrowth of bacteria. The diagnosis is SIBO. In type-M (c), gas in the large intestine and the small intestine was increased as a result of fermentation in the large intestine and the small intestine. The diagnosis is IBS with SIBO, or SIBO with IBS. 


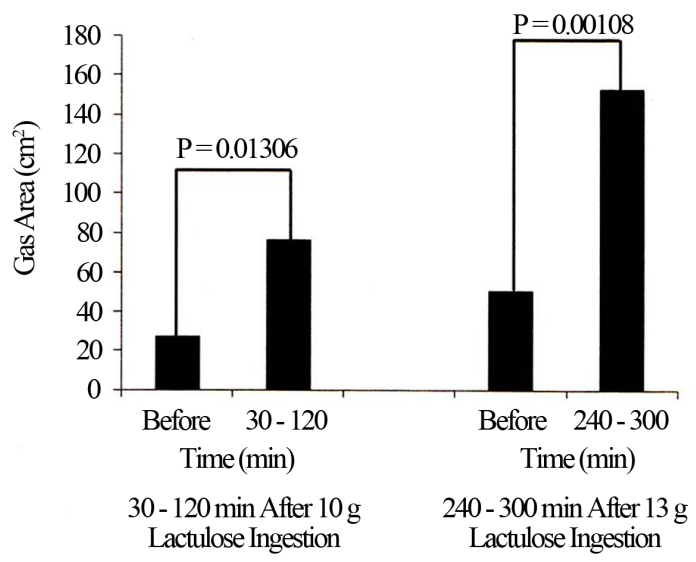

\begin{abstract}
Figure 4. Changes in the large intestine gas region in the type-L pattern. Dose of lactulose and time frame for radiography was performed with two methods: $10 \mathrm{~g}$ lactulose and observation over $120 \mathrm{~min}$; and $13 \mathrm{~g}$ lactulose and observation over 240 - $300 \mathrm{~min}$. Comparison of the two methods to control (prior to lactulose ingestion) for a type-L pattern of gas formation, where $\mathrm{P}=0.01306$ and $\mathrm{P}=0.00108$, respectively.
\end{abstract}

in IBS correlate with intestinal gas volume in plain abdominal X-ray and abdominal CT images. Here, adjustments were made in the methodology, namely increasing the dose of lactulose and extending the time period for radiography. The results demonstrated that at a dose of $10 \mathrm{~g}$ lactulose and an observation time of two hours, patients displayed no symptoms, and the gas volume was only slightly increased. Lactulose breath test was first reported in 1972 by Bond and Levitt [27]. In their study, excretion of hydrogen gas continued until 5 hours after $13 \mathrm{~g}$ lactulose ingestion. For that reason, in the second half of the study, lactulose was increased, and the observation time was extended. When the dose of lactulose was increased (13 g/50 kg), and the observation time for the lactulose challenge was extended to 240 - 300 minutes, the results clearly demonstrated an increase in the gas produced in IBS patients.

The increase in the volume of large intestinal gas was more noticeable during the time frame of 240 - 300 minutes than during $30-60$ minutes. In order to diagnose this pattern, it might be sufficient to observe an increase in large intestinal gas in the absence of increased small intestinal gas and to detect an increase at a single time point rather than over 240 - 300 minutes. Therefore, clinical management of the patient may require the ability to visualize a marked difference in the gas volume/pattern on the basis of two radiographs, one before and one after 240 - 300 min.

For LBT, it is widely accepted that a peak of hydrogen gas within 90 minutes is evidence of gas produced in the small intestine. In previous reports, the transit time from the mouth to the cecum has been shown to be on average 65 min or up to 85 minutes [28] [29]. In a recent study where a wireless motility capsule (Smart-Pill) was used to assess intestinal motility, small intestinal transit time in SIBO patients was found to be delayed compared to controls. Specifically, small intestinal transit time in healthy controls was on average, 4.25 hours, whereas small intestinal transit time in IBS of LBT positive patients was 6.95 hours [25]. Thus, small intestinal transit time was slow when the peak of the breath hydrogen in the LBT occurred within 90 minutes.

Two patients (patient 6 and patient 9) with increased gas of the small intestine might in fact be SIBO. If this hypothesis is correct, a type-S pattern (patient 9) might be indicative of pure SIBO, whereas a type-M pattern (patient 6) might be consistent with simultaneous IBS and SIBO. In the type-M pattern, small intestinal gas was decreased at 4 hours after the peak at $120 \mathrm{~min}$. However, large intestinal gas continued to increase. If the diagnosis of SIBO on the basis of the LBT is correct, then there might be a time lag between the increase in the LBT and the increase in small intestinal gas.

In previous studies investigating gas volume in IBS, a gas volume score was devised [21]-[23]. In this approach, the gas image was traced from the radiograph on the computer screen, and the number of pixels correlating to the total traced area was used as the gas volume score. However, a consensus for a correlation between increased gas and IBS was not obtained. One explanation might be the method of evaluation of the gas volume. In these studies, the total gas volume was represented as a single measurement of the entire digestive tract rather 
than as multiple measurements extracted from each of three anatomical locations, the stomach, the small intestine, and the large intestine. Furthermore, in the studies investigating the relationship between the LBT and gas volume, X-ray imaging was performed only once, either before or immediately after ingestion of the lactulose. In the present study, results demonstrated that over time, the gas volume, even in individuals, changed. Therefore, a single image during the time course might be insufficient.

The conclusions of this study are limited as the work was conducted on a small cohort of IBS patients. However, increases in small intestinal gas were still observed in two patients (14.3\%). In 2000, eradication by antibiotics was recommended because many IBS patients were also diagnosed with SIBO based on result of the LBT [4]. There is uncertainty, however, concerning the diagnostic criteria of SIBO, and thus, the relationship of IBS and SIBO is ambiguous. Nevertheless, the use of antibiotics has been recommended as a therapy for IBS, in order to control gastrointestinal bacterial overgrowth [6] [16].

Finally, a change in diet has also been proposed as a strategy to alleviate symptoms of IBS/SIBO. Because fermentable oligosaccharides, disaccharides, monosaccharides, and polyols (FODMAP) produce gas and osmotically active byproducts, causing an increase in fluid in the intestines, a low FODMAP diet has been tested and found to improve the gas symptoms of IBS [30] [31]. However, there are no indicators to determine which patients will derive a benefit from a low FODMAP diet. As lactulose falls under the category of high FODMAP, confirmation of increasing gas in the colon after ingestion of lactulose, as observed in this study, is potentially a reason to practice a low FODMAP diet. In SIBO, if the symptoms of patients are caused by increased gas from fermentation, a low FODMAP diet might help to alleviate the symptoms as well. The implementation of such strategies is preferable, as the overuse of antimicrobial agents presents specific health risks overall, namely bacterial resistance [32]. Adaptation of eradication therapy, therefore, should be limited to the patient with increased small intestinal gas after ingestion of lactulose and without significant improvement on a low FODMAP diet.

\section{Author Contribution}

Yoshiharu Uno: study design, data analysis, and manuscript preparation.

\section{References}

[1] Ghoshal, U.C. and Srivastava, D. (2014) Irritable Bowel Syndrome and Small Intestinal Bacterial Overgrowth: Meaningful Association or Unnecessary Hype. World Journal of Gastroenterology, 20, 2484-2491. http://dx.doi.org/10.3748/wjg.v20.i10.2482

[2] William, B., Ishaq, N., Bolin, T.D., et al. (2014) Overgrowth of the Indigenous Gut Microbiome and Irritable Bowel Syndrome. World Journal of Gastroenterology, 20, 2449-2455. http://dx.doi.org/10.3748/wjg.v20.i10.2449

[3] Rana, S.V. and Malik, A. (2014) Breath Tests and Irritable Bowel Syndrome. World Journal of Gastroenterology, 20, 7587-601. http://dx.doi.org/10.3748/wjg.v20.i24.7587

[4] Sachdev, A.H. and Pimentel, M. (2012) Antibiotics for Irritable Bowel Syndrome: Rationale and Current Evidence. Current Gastroenterology Reports, 14, 439-445. http://dx.doi.org/10.1007/s11894-012-0284-2

[5] Sachdev, A.H. and Pimentel, M. (2013) Gastrointestinal Bacterial Overgrowth: Pathogenesis and Clinical Significance. Therapeutic Advances in Chronic Disease, 4, 223-231. http://dx.doi.org/10.1177/2040622313496126

[6] Pimentel, M., Chow, E.J. and Lin, H.C. (2000) Eradication of Small Intestinal Bacterial Overgrowth Reduces Symptoms of Irritable Bowel Syndrome. The American Journal of Gastroenterology, 95, 3503-3506. http://dx.doi.org/10.1111/j.1572-0241.2000.03368.x

[7] Nucera, G., Gabrielli, M., Lupascu, A., et al. (2005) Abnormal Breath Tests to Lactose, Fructose and Sorbitol in Irritable Bowel Syndrome May Be Explained by Small Intestinal Bacterial Overgrowth. Alimentary Pharmacology \& Therapeutics, 21, 1391-1395. http://dx.doi.org/10.1111/j.1365-2036.2005.02493.x

[8] Posserud, I., Stotzer, P.O., Björnsson, E.S., et al. (2007) Small Intestinal Bacterial Overgrowth in Patients with Irritable Bowel Syndrome. Gut, 56, 802-808. http://dx.doi.org/10.1136/gut.2006.108712

[9] Scarpellini, E., Giorgio, V., Gabrielli, M., et al. (2009) Prevalence of Small Intestinal Bacterial Overgrowth in Children with Irritable Bowel Syndrome: A Case-Control Study. The Journal of Pediatrics, 155, 416-420. http://dx.doi.org/10.1016/j.jpeds.2009.03.033

[10] Ford, A.C., Spiegel, B.M., Talley, N.J., et al. (2009) Small Intestinal Bacterial Overgrowth in Irritable Bowel Syndrome: Systematic Review and Meta-Analysis. Clinical Gastroenterology and Hepatology, 7, 1279-1286. http://dx.doi.org/10.1016/j.cgh.2009.06.031 
[11] Parodi, A., Dulbecco, P., Savarino, E., et al. (2009) Positive Glucose Breath Testing Is More Prevalent in Patients with IBS-Like Symptoms Compared with Controls of Similar Age and Gender Distribution. Journal of Clinical Gastroenterology, 43, 962-966. http://dx.doi.org/10.1097/MCG.0b013e3181a099a5

[12] Reddymasu, S.C., Sostarich, S. and McCallum, R.W. (2010) Small Intestinal Bacterial Overgrowth in Irritable Bowel Syndrome: Are There Any Predictors? BMC Gastroenterology, 10, 23. http://dx.doi.org/10.1186/1471-230X-10-23

[13] Ghoshal, U.C., Kumar, S., Mehrotra, M., et al. (2010) Frequency of Small Intestinal Bacterial Overgrowth in Patients with Irritable Bowel Syndrome and Chronic Non-Specific Diarrhea. Journal of Neurogastroenterology and Motility, 16, 40-46. http://dx.doi.org/10.5056/jnm.2010.16.1.40

[14] Bratten, J.R., Spanier, J. and Jones, M.P. (2008) Lactulose Breath Testing Does Not Discriminate Patients with Irritable Bowel Syndrome from Healthy Controls. The American Journal of Gastroenterology, 103, 958-963. http://dx.doi.org/10.1111/j.1572-0241.2008.01785.x

[15] Vanner, S. (2008) The Lactulose Breath Test for Diagnosing SIBO in IBS Patients: Another Nail in the Coffin. The American Journal of Gastroenterology, 103, 964-965. http://dx.doi.org/10.1111/j.1572-0241.2008.01798.x

[16] Pimentel, M., Lembo, A., Chey, W.D., et al. (2011) Rifaximin Therapy for Patients with Irritable Bowel Syndrome without Constipation. New England Journal of Medicine, 364, 22-32. http://dx.doi.org/10.1056/NEJMoa1004409

[17] Vanner, S. (2008) The Small Intestinal Bacterial Overgrowth. Irritable Bowel Syndrome Hypothesis: Implications for Treatment. Gut, 57, 1315-1321. http://dx.doi.org/10.1136/gut.2007.133629

[18] Lacy, B.E., Gabbard, S.L. and Crowell, M.D. (2011) Pathophysiology, Evaluation, and Treatment of Bloating: Hope, Hype, or Hot Air? Gastroenterology and Hepatology, 7, 729-739.

[19] Harder, H., Serra, J., Azpiroz, F., et al. (2003) Intestinal Gas Distribution Determines Abdominal Symptoms. Gut, 52, 1708-1713. http://dx.doi.org/10.1136/gut.52.12.1708

[20] Gabrielli, M., D’Angelo, G., Di Rienzo, T., et al. (2013) Diagnosis of Small Intestinal Bacterial Overgrowth in the Clinical Practice. European Review for Medical and Pharmacological Sciences, 17, 30-35.

[21] Koide, A., Yamaguchi, T., Odaka, T., et al. (2000) Quantitative Analysis of Bowel Gas Using Plain Abdominal Radiograph in Patients with Irritable Bowel Syndrome. The American Journal of Gastroenterology, 95, 1735-1741. http://dx.doi.org/10.1111/j.1572-0241.2000.02189.x

[22] Morken, M.H., Berstad, A.E., Nysaeter, G., et al. (2007) Intestinal Gas in Plain Abdominal Radiographs Does Not Correlate with Symptoms after Lactulose Challenge. European Journal of Gastroenterology \& Hepatology, 19, 589593. http://dx.doi.org/10.1097/MEG.0b013e328133f2e7

[23] Youn, Y.H., Park, J.S., Jahng, J.H., et al. (2011) Relationships among the Lactulose Breath Test, Intestinal Gas Volume, and Gastrointestinal Symptoms in Patients with Irritable Bowel Syndrome. Digestive Diseases and Sciences, 56, 2059-2066. http://dx.doi.org/10.1007/s10620-011-1569-2

[24] Mc Williams, S.R., Mc Laughlin, P.D., O’Connor, O.J., et al. (2012) Computed Tomography Assessment of Intestinal Gas Volumes in Functional Gastrointestinal Disorders. Journal of Neurogastroenterology and Motility, 18, 419-425. http://dx.doi.org/10.5056/jnm.2012.18.4.419

[25] Roland, B.C., Ciarleglio, M.M., Clarke, J.O., et al. (2015) Small Intestinal Transit Time Is Delayed in Small Intestinal Bacterial Overgrowth. Journal of Clinical Gastroenterology, 49, 571-576.

[26] Longstreth, G.F., Thompson, W.G., Chey, W.D., et al. (2006) Functional Bowel Disorders. Gastroenterology, 130, 1480-1491. http://dx.doi.org/10.1053/j.gastro.2005.11.061

[27] Bond Jr., J.H. and Levitt, M.D. (1972) Use of Pulmonary Hydrogen $\left(\mathrm{H}_{2}\right)$ Measurements to Quantitate Carbohydrate Absorption. Study of Partially Gastrectomized Patients. Journal of Clinical Investigation, 51, 1219-1225. http://dx.doi.org/10.1172/JCI106916

[28] Ghoshal, U.C., Ghoshal, U., Ayyagari, A., et al. (2003) Tropical Sprue Is Associated with Contamination of Small Bowel with Aerobic Bacteria and Reversible Prolongation of Orocecal Transit Time. Journal of Gastroenterology and Hepatology, 18, 540-547. http://dx.doi.org/10.1046/j.1440-1746.2003.03006.x

[29] Lu, C.L., Chen, C.Y., Chang, F.Y., et al. (1998) Characteristics of Small Bowel Motility in Patients with Irritable Bowel Syndrome and Normal Humans: An Oriental Study. Clinical Science, 95, 165-169. http://dx.doi.org/10.1042/cs0950165

[30] Gibson, P.R. and Shepherd, S.J. (2005) Personal View: Food for Thought-Western Lifestyle and Susceptibility to Crohn's Disease. The FODMAP Hypothesis. Alimentary Pharmacology and Therapeutics, 21, 1399-1409. http://dx.doi.org/10.1111/j.1365-2036.2005.02506.x

[31] Gibson, P.R. and Shepherd, S.J. (2012) Foodchoiceas a Key Management Strategy for Functional Gastrointestinal Symptoms. The American Journal of Gastroenterology, 107, 657-666. http://dx.doi.org/10.1038/ajg.2012.49

[32] Blaser, M. (2011) Antibiotic Overuse: Stop the Killing of Beneficial Bacteria. Nature, 476, 393-394. 